\title{
Meningitis and epididymitis caused by Toscana virus infection imported to Switzerland diagnosed by metagenomic sequencing: a case report
}

\author{
Fabian Tschumi ${ }^{1}$, Stefan Schmutz ${ }^{2}$, Verena Kufner ${ }^{2}$, Maike Heider ${ }^{3}$, Fiona Pigny ${ }^{4}$, Bettina Schreiner ${ }^{3}$, \\ Riccarda Capaul ${ }^{2}$, Yvonne Achermann $^{1+}$ and Michael Huber ${ }^{2 *+}$ (D)
}

\begin{abstract}
Background: We report a rare case of Toscana virus infection imported into Switzerland in a 23-year old man who travelled to Imperia (Italy) 10 days before onset of symptoms. Symptoms included both meningitis and as well epididymitis. This is only the fourth case of Toscana virus reported in Switzerland.

Case presentation: The patient presented with lymphocytic meningitis and scrotal pain due to epididymitis. Meningitis was initially treated with ceftriaxone. Herpes simplex, tick-borne encephalitis, enterovirus, measles, mumps, rubella and Treponema pallidum were excluded with specific polymerase chain reaction (PCR) or serology. In support of routine diagnostic PCR and serology assays, unbiased viral metagenomic sequencing was performed of cerebrospinal fluid and serum. Toscana virus infection was identified in cerebrospinal fluid and the full coding sequence could be obtained. Specific PCR in cerebrospinal fluid and blood and serology with Immunoglobulin (Ig) $\mathrm{M}$ and IgG against Toscana virus confirmed our diagnosis. Neurological symptoms recovered spontaneously after 5 days.

Conclusions: This case of Toscana virus infection highlights the benefits of unbiased metagenomic sequencing to support routine diagnostics in rare or unexpected viral infections. With increasing travel histories of patients, physicians should be aware of imported Toscana virus as the agent for viral meningitis and meningoencephalitis.
\end{abstract}

Keywords: Toscana virus, Meningitis, Epididymitis, Clinical metagenomics, Switzerland

\section{Background}

Viruses are the most common cause of aseptic meningitis. Depending on the season and region, a multitude of viral pathogens can produce meningitis, for example enteroviruses, tick-borne encephalitis virus, paramyxoviruses such as mumps virus, influenza virus, as well as herpesviruses. They can be detected by specific, routine PCR or serology. A rapid diagnosis of the pathogen is crucial to avoid unnecessary antibiotic or anti-herpesvirus treatment. However, in the majority of cases, the pathogen remains unknown. Metagenomic sequencing is based on

\footnotetext{
* Correspondence: huber.michael@virology.uzh.ch

${ }^{\dagger}$ Yvonne Achermann and Michael Huber contributed equally to this work. ${ }^{2}$ Institute of Medical Virology, University of Zurich, Winterthurerstrasse 190, 8057 Zurich, Switzerland

Full list of author information is available at the end of the article
}

unbiased detection of nucleic acids isolated from clinical samples [1]. Hence, it can detect rare viruses that are not included in routine diagnostic panels and viruses with sequence variations that would otherwise be missed [2]. Here, we used clinical metagenomic sequencing in a patient suffering from viral meningitis and epididymitis in whom no pathogen was found with routine molecular testing.

\section{Case presentation Case report}

A 23-year-old previously healthy student from the canton of Zurich, Switzerland, presented in September 2018 with headache, nausea and photophobia for 2 days and testicular pain for one day. 10 days before onset of

(c) The Author(s). 2019 Open Access This article is distributed under the terms of the Creative Commons Attribution 4.0 International License (http://creativecommons.org/licenses/by/4.0/), which permits unrestricted use, distribution, and 
symptoms, he returned from a 4-day trip to Imperia (Liguria, Italy). Upon admission, the patient had fever $\left(38.0^{\circ} \mathrm{C}\right)$ with normal heart rate $(77 \mathrm{bpm})$ and blood pressure $(137 / 82 \mathrm{mmHg})$. Physical examination revealed signs of meningeal irritation in the absence of focal neurological deficits. There were no skin abnormalities. A swollen and tender right testicle was noted. An ultrasound of the right scrotum showed a hypoechogenic inhomogeneous parenchyma and a discrete hydrocele which was compatible with epididymitis. The serum laboratory tests showed a slightly elevated C-reactive protein level of $13.0 \mathrm{mg} / \mathrm{l}$ while leucocytes were normal $(8.82 \mathrm{G} / \mathrm{l})$. A Human immunodeficiency virus (HIV)screening test was negative.

A computed tomography scan of the brain without contrast excluded brain swelling with signs of elevated intracranial pressure. A cerebrospinal fluid (CSF) examination revealed a pleocytosis of 53 cells $/ \mu$ l consisting primarily of lymphocytes (70\%) and monocytes/macrophages (23\%), normal glucose, increased lactate (3.3 $\mathrm{mmol} / \mathrm{l}$ ) and moderately increased total protein levels $(0.821 \mathrm{~g} / \mathrm{l})$.

An empirical therapy was started with intravenous acyclovir and ceftriaxone to cover bacterial and herpesvirus meningitis while awaiting CSF PCR and culture results.

Two days later, Enterovirus, varicella zoster virus, herpes simplex virus (HSV)-1 and HSV-2 could be excluded by PCR tests and tick-borne encephalitis virus by negative IgM in CSF. Serum IgM was negative for Epstein Barr virus, Measles, Mumps, Rubella, Treponema pallidum, and Borrelia burgdorferi. Since all tests including conventional cultures after 4 days were unremarkable, unbiased metagenomic virus sequencing of the CSF and serum was performed. Finally, fungal, bacterial and mycobacterial cultures of CSF remained negative after prolonged cultivation time.

Metagenomic sequencing of the CSF sample detected 284 reads of the species Sandfly fever Naples phlebovirus, all of them belonging to the genotype Toscana virus (TOSV). No viral reads were found in serum. Quantitative PCR specific for TOSV [3] performed later for confirmation was positive in CSF (ct value 25.1) and also weak positive in serum (ct value 37.8). In TOSV serology, IgG and IgM were strongly positive (Sandfly fever virus Mosaic 1 types Sicilian, Naples, Toscana, Cyprus IgG and IgM assay, EuroImmun, Luebeck, Germany). There was a weak positive signal for IgG and IgM against Sicilian virus probably due to cross reactivity (Additional file 1: Figure S1).

Acyclovir was stopped after obtaining the negative herpesvirus PCR results, whereas the consulting urologist recommended to complete the course of the antibiotic treatment (over 10 days, i.v. ceftriaxone, switched to p.o. ciprofloxacin upon discharge). After 5 days, the headache and testicular pain resolved completely, and the patient was discharged.

\section{Unbiased metagenomic sequencing}

Briefly, samples were centrifuged and filtered. Total nucleic acids were extracted followed by reverse transcription with random hexamers and second strand synthesis in separate reactions for RNA and DNA genomes. For the RNA workflow, DNase treatment was included before reverse transcription. DNA and RNA preparations were kept separate for constructing sequencing libraries with the NexteraXT protocol (Illumina, San Diego, CA). Libraries were sequenced on a MiSeq for $1 \times 150$ cycles. Reads were analyzed with a dedicated bioinformatic pipeline "VirMet" (github.com/medvir/VirMet/releases/ tag/v1.1.1) [2]. The raw viral sequencing reads have been uploaded to zenodo (doi: https://doi.org/10.5281/ zenodo.2545561).

\section{Genome analysis}

To generate a consensus sequence of the identified TOSV, all reads were iteratively aligned using SmaltAlign (github.com/medvir/SmaltAlign). In total, 4491 reads aligned and the full coding sequences could be reconstructed. However, a gap of 23 nucleotides remained in segment $\mathrm{S}$ at the position of the translation stop hairpin signal found in all ambisense viruses (Fig. 1a). Conceivably, this region was not efficiently reverse transcribed at the conditions used in our protocol. We closed the gap by sequencing a short amplicon using specific primers (Additional file 1). The full genome sequences have been deposited to GenBank (GenBank IDs MK422498 to MK422500). Phylogenetic analysis showed that the isolate belongs to the B lineage of TOSV (Fig. 1b).

\section{Discussion and conclusions}

Using unbiased metagenomic sequencing we identified a case of imported Toscana virus (TOSV) infection in a 23-year old man. To the best of our knowledge, this is only the fourth reported case of TOSV infection in Switzerland [3].

Toscana virus belongs to the species Sandfly fever Naples phlebovirus in the genus Phlebovirus within the family Phenuiviridae. In Eurasia and Africa, TOSV and other phleboviruses are transmitted by phlebotomine flies, which are widely distributed around the Mediterranean, in North Africa, the Middle East, India and central Asia. High seroprevalence has been recorded in humans and domestic animals in areas where sandflies are present [4]. A seroprevalence study of TOSV between 2013 and 2014 in Siena (central Italy) showed with $26.75 \%$ the endemic circulation of TOSV in this area [5]. The incubation period ranges from a few days to 


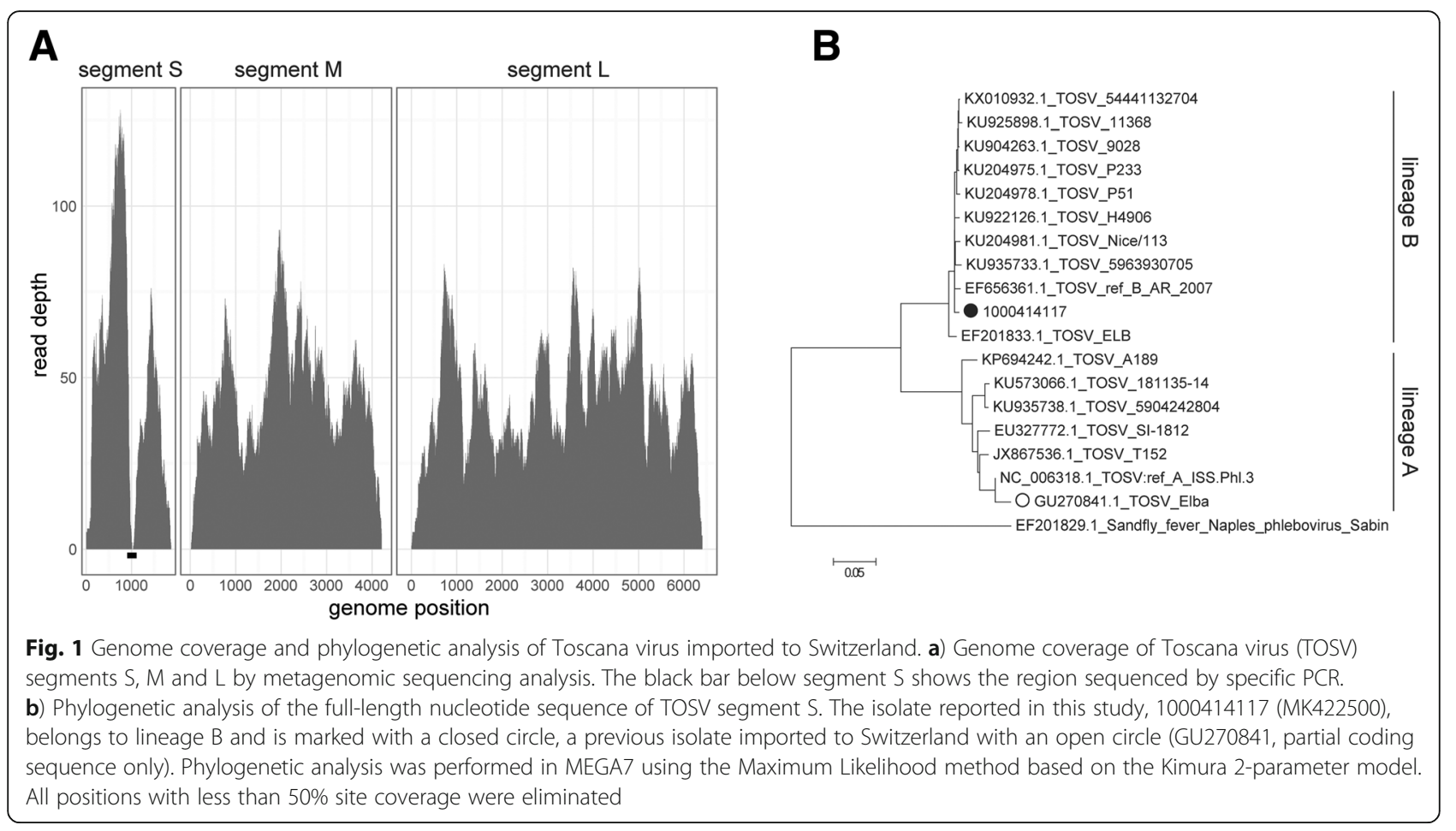

approximately 2 weeks. Most TOSV infections, especially in young people, are asymptomatic or paucisymptomatic with a transient febrile illness (sandfly fever). However, during peak sandfly activity in summer, TOSV infection is thought to be the main etiologic agent of aseptic meningitis in Italy and other endemic regions [6]. Typical clinical findings of TOSV infections are a headache, fever, rash and gastrointestinal symptoms such as nausea and vomiting [7], which can also be found in meningitis caused by other pathogens. The disease is usually selflimiting and does not need hospitalization. However, occasionally severe complications such as meningoencephalitis have occurred. Interestingly, epididymitis-orchitis, as also present in our patient, has been described in three published cases as an unusual manifestation of TOSV infection [8-10] without having further associations in larger studies. A sexual transmission has not been described.

Only three previous cases of imported TOSV cases into Switzerland have been published. These include two men, one 17-year old and one in his twenties, who were both visiting the Island of Elba [11, 12]; and a 61-year old man, who was in Tuscany [3]. All of them recovered within five days. In two of the cases, a virus of genotype TOSV lineage A was detected (GU270841) [12] or suggested [3], while in one case the lineage remained unknown [11]. TOSV strains are subdivided into three lineages that are more or less congruent with geography $[13,14]$. In Italy, lineage A is predominant, however, cocirculation of two genotypes has been shown previously in southeastern France close to the origin of the isolate in this study [15]. To our knowledge, no difference in clinical presentation has been described between the two lineages.

We can't exclude other unrecognized or unpublished cases in Switzerland since in general no routine viral metagenomics or TOSV serology is performed in patients with aseptic meningitis. Our diagnosed TOSV infection case highlights the benefits of unbiased metagenomic virus sequencing for rare or unexpected viral infections. A rapid identification of a viral etiology may have direct consequences for treatment and limit the unnecessary prescription of antibiotics. With increasing travel histories of patients, physicians should be aware of imported TOSV as the agent for viral meningitis and meningoencephalitis.

\section{Additional file}

Additional file 1: Figure S1. Toscana virus lgG and IgM Serology. Methods. TOSV Sequencing and PCR Primers. (PDF 4478 kb)

\section{Abbreviations}

CSF: Cerebrospinal fluid; HIV: Human immunodeficiency virus; HSV: Herpes simplex virus; Ig: Immunoglobulin; PCR: Polymerase chain reaction; TOSV: Toscana Virus

Acknowledgments

We thank Cyril Shah for help with the design of PCR primers. 


\section{Authors' contributions}

$\mathrm{FT}, \mathrm{MHe}$ and BS cared for the patient and provided clinical data and materials. SS, VK and FP performed sequencing experiments and PCR assays. $F T, R C$ and $Y A$ analyzed and interpreted routine diagnostic results. FT, YA and $\mathrm{MHu}$ wrote the manuscript. All authors read and approved the final manuscript.

\section{Funding}

This work was funded by the Clinical Research Priority Program 'Comprehensive Genomic Pathogen Detection' of the University of Zurich. The funding body did not have any role in the design of the study, in the collection, analysis, and interpretation of data and in writing the manuscript.

\section{Availability of data and materials}

The raw viral sequencing reads supporting the conclusions of this article are available in the zenodo repository (doi: https://doi.org/10.5281/zenodo. 2545561). The full genome sequences of the identified TOSV isolate 1000414117 are available in GenBank (MK422498 to MK422500)

\section{Ethics approval and consent to participate}

Not applicable.

\section{Consent for publication}

Written informed consent for publication has been obtained from the patient.

\section{Competing interests}

The authors declare that they have no competing interests.

\section{Author details}

'Division of Infectious Diseases and Hospital Epidemiology, University Hospital Zurich, University of Zurich, Rämistrasse 100, 8091 Zurich, Switzerland. Institute of Medical Virology, University of Zurich, Winterthurerstrasse 190, 8057 Zurich, Switzerland. ${ }^{3}$ Department of Neurology, University Hospital Zurich, Rämistrasse 100, 8091 Zurich, Switzerland.

${ }^{4}$ Virology Laboratory, Geneva University Hospitals, Rue Gabrielle-Perret-Gentil 4, 1205 Geneva, Switzerland.

Received: 18 February 2019 Accepted: 27 June 2019

Published online: 08 July 2019

\section{References}

1. Brown JR, Bharucha T, Breuer J. Encephalitis diagnosis using metagenomics: application of next generation sequencing for undiagnosed cases. J Inf Secur. 2018;76(3):225-40

2. Lewandowska DW, Zagordi $O$, Zbinden A, Schuurmans MM, Schreiber $P$, Geissberger FD, Huder JB, Boni J, Benden C, Mueller NJ, et al. Unbiased metagenomic sequencing complements specific routine diagnostic methods and increases chances to detect rare viral strains. Diagn Microbiol Infect Dis. 2015;83(2):133-8.

3. Cordey S, Petty TJ, Docquier M, Turin L, Cherpillod P, Emonet S, Zdobnov EM, Kaiser L. Toscana virus meningitis case in Switzerland: an example of the ezVIR bioinformatics pipeline utility for the identification of emerging viruses. Clin Microbiol Infect. 2015;21(4):387.e381-4.

4. Alkan C, Bichaud L, de Lamballerie X, Alten B, Gould EA, Charrel RN. Sandflyborne phleboviruses of Eurasia and Africa: epidemiology, genetic diversity, geographic range, control measures. Antivir Res. 2013;100(1):54-74.

5. Marchi S, Trombetta CM, Kistner O, Montomoli E. Seroprevalence study of Toscana virus and viruses belonging to the Sandfly fever Naples antigenic complex in central and southern Italy. J Infect Public Health. 2017;10(6):866-9.

6. Cusi MG, Savellini GG, Zanelli G. Toscana virus epidemiology: from Italy to beyond. Open Virol J. 2010;4(2):22-8.

7. Di Nicuolo G, Pagliano P, Battisti S, Starace M, Mininni V, Attanasio V, Faella FS. Toscana virus central nervous system infections in southern Italy. J Clin Microbiol. 2005;43(12):6186-8.

8. Zanelli G, Bianco C, Cusi MG. Testicular involvement during Toscana virus infection: an unusual manifestation? Infection. 2013;41(3):735-6.

9. Baldelli F, Ciufolini MG, Francisci D, Marchi A, Venturi G, Fiorentini C, Luchetta ML, Bruto L, Pauluzzi S. Unusual presentation of life-threatening Toscana virus meningoencephalitis. Clin Infect Dis. 2004;38(4):515-20.

10. Gonen OM, Sacagiu T. Sensory polymyeloradiculopathy associated with Toscana virus infection. J Neuro-Oncol. 2013;19(5):508-10.
11. Sonderegger $B$, Hachler $H$, Dobler G, Frei M. Imported aseptic meningitis due to Toscana virus acquired on the island of Elba, Italy, august 2008. Euro Surveill. 2009;14(1).

12. Gabriel M, Resch C, Günther S, Schmidt-Chanasit J. Toscana virus infection imported from Elba into Switzerland. Emerg Infect Dis. 2010;16(6):1034-6.

13. Baklouti A, Leparc-Goffart I, Piorkowski G, Coutard B, Papageorgiou N, de Lamballerie $X$, Charrel RN. Complete coding sequences of six Toscana virus strains isolated from human patients in France. Genome Announc. 2016;4(3).

14. Baggieri M, Marchi A, Bucci P, Nicoletti L, Magurano F. Genetic variability of the $S$ segment of Toscana virus. Virus Res. 2015;200:35-44.

15. Charrel RN, Izri A, Temmam S, Delaunay P, Toga I, Dumon H, Marty P, de Lamballerie X, Parola P. Cocirculation of 2 genotypes of Toscana virus, southeastern France. Emerg Infect Dis. 2007;13(3):465-8.

\section{Publisher's Note}

Springer Nature remains neutral with regard to jurisdictional claims in published maps and institutional affiliations.
Ready to submit your research? Choose BMC and benefit from:

- fast, convenient online submission

- thorough peer review by experienced researchers in your field

- rapid publication on acceptance

- support for research data, including large and complex data types

- gold Open Access which fosters wider collaboration and increased citations

- maximum visibility for your research: over $100 \mathrm{M}$ website views per year

At BMC, research is always in progress.

Learn more biomedcentral.com/submissions 